\title{
Determination of Regulator Parameters and Transient Analysis of Modified Self-commutating CSI-fed IM Drive
}

\begin{abstract}
A. K. Pandey ${ }^{\dagger}$ and S. M. Tripathi*
Abstract - In this paper, an attempt has been made to design the current and speed proportional and integral (PI) regulators of self-commutating current source inverter-fed induction motor drive having capacitors at the machine end and to investigate the transient performance of the same for step changes in reference speed. The mathematical model of the complete drive system is developed in closed loop, and the characteristic equations of the systems are derived using perturbation about steady-state operating point in order to develop the characteristic equations. The D-partition technique is used for finding the stable region in the parametric plane. Frequency scanning technique is used to confirm the stability region. Final selection of the regulator parameters is done by comparing the transient response of the current and speed loops for step variations in reference. The performance of the drive is observed analytically through MATLAB simulation.
\end{abstract}

Keywords: Current source inverter, D-partition technique, Frequency scanning, Induction motor drive, Speed and current regulator, Transient performance

\section{Nomenclature}

$\begin{array}{ll}d, q & \text { Direct and quadrature axes } \\ v_{a s,}, v_{b s,}, v_{c s} & \begin{array}{l}\text { Phase voltages of the PWM inverter } \\ v_{d s}^{e}\end{array} \\ i_{d s}^{e} & \text { d-axis stator voltage in synchronously rotating reference frame } \\ v_{q s}^{e} & \text { q-axis stator current in synchronous rotating reference frame } \\ i_{q s}^{e} & \text { q-axis stator current in synchronously rotating reference frame } \\ i_{d r}^{e} & \text { d-axis rotor current in synchronously rotating reference frame } \\ i_{q r}^{e} & \text { q-axis rotor current in synchronously rotating reference frame } \\ i_{a s}, i_{b s}, i_{c s} & \text { Line currents of PWM inverter } \\ I_{D C} & \text { DC link current } \\ I_{a c t} & \text { Active component of stator current } \\ I_{a c t}^{*} & \text { Reference active component of stator current } \\ I_{r e a c t} & \text { Reactive component of stator current } \\ I_{r e a c t}^{*} & \text { Reference reactive component of stator current } \\ \omega_{e} & \text { Synchronous speed of the induction motor } \\ \omega_{r} & \text { Rotor speed of the induction motor } \\ \omega_{r}^{*} & \text { Reference speed } \\ \omega_{s l} & \text { Slip speed of the induction motor } \\ \omega_{s l}^{*} & \text { Reference slip speed } \\ & \end{array}$

$\dagger$ Corresponding Author: Department of Electrical Engineering, Kamla Nehru Institute of Technology, Sultanpur - 228118 (U.P.) India. (maniexcel@yahoo.co.in)

* Department of Electrical Engineering, Madan Mohan Malaviya Engineering College, Gorakhpur - 273010 (U.P.) India. (akp1234@gmail.com)

Received: March 8, 2010; Accepted: November 2, 2010

\author{
Flux linkages of the d-axis of the stator windings \\ Flux linkages of the q-axis of the stator windings \\ Flux linkage of the d-axis of the rotor winding \\ Flux linkage of the q-axis of the rotor winding \\ Reference DC link current \\ Input voltage of the inverter \\ Rectifier output voltage \\ Resistance of DC link inductor \\ Inductance of DC link inductor \\ Resistance of stator winding per phase \\ Self-inductance of stator winding per phase \\ Resistance of rotor winding per phase \\ Self inductance of rotor winding per phase \\ Mutual inductance per phase \\ $\mathrm{L}_{\mathrm{s}} \mathrm{L}_{\mathrm{r}}-\mathrm{L}_{\mathrm{m}}^{2}$ \\ Capacitance per phase \\ Moment of inertia in $\mathrm{kg}-\mathrm{m}^{2}$ \\ Viscous friction coefficient \\ Pulse width of PWM rectifier \\ Line-to-line input voltage of the rectifier \\ Number of poles \\ Instantaneous phase current of capacitor \\ Instantaneous stator phase voltage \\ d-axis capacitor current in synchronously rotating reference frame \\ q-axis capacitor current in synchronously rotating reference frame \\ Proportional gain of current regulator \\ Integral gain of current regulator \\ Proportional gain of speed regulator \\ Integral gain of speed regulator \\ Differential operator $(d / d t)$ or complex frequency
}




$\begin{array}{ll}\text { Suffix } 0 & \text { Represents a variable in steady-state conditions } \\ \sigma & \text { Degree of relative stability } \\ \omega & \text { Natural frequency } \\ k_{1} & \text { Slope of stator active current }\left(I_{\text {act }}\right) \text { vs. slip speed }\left(\omega_{s l}\right) \\ k_{2} & \text { Slope of stator reactive current vs. slip speed }\left(\omega_{s l}\right) \\ k_{l 1} & \frac{\text { Rated value of capacitor current per phase }}{\left[\text { Rated angular frequency }\left(\omega_{\mathrm{e}}\right)\right]^{2}}\end{array}$

\section{Introduction}

Variable and smooth speed control is the mandatory requirement for any industrial drive. The speed control of induction motors over a wide range can be done with the help of variable frequency VSI or CSI. Due to the controlled current operation of the inverter, slip-regulated CSI is preferred over VSI. The current source at the front end makes the system naturally capable of power regeneration [1]-[4]. In this paper, the closed loop scheme of selfcommutating current source inverter-fed induction motor drive employing two PI regulators - one in the outer speed feedback loop and other in the inner current feedback loop, is discussed. The outer speed loop is used to obtain the reference DC link current from the slip speed, whereas the inner current loop regulates the DC link current according to the load torque demand [5]. The design of the feedback loop parameters requires complete analysis and simulation of the entire drive. The parameters for current and speed PI regulators of a self-commutating CSI-fed induction motor drive are designed on the basis of system relative stability, frequency scanning, and transient response of the drive.

\section{System Description}

The CSI-fed induction motor drive consists of a threephase AC source, a PWM rectifier, a DC link smoothening reactor, a current-controlled inverter, a three-phase squirrel cage induction motor, and a three-phase capacitor bank, as shown in Fig. 1. A fast-response speed-regulating drive can be realized by incorporating PI regulators in the feedback loop [6]-[8]. Two PI regulators are used - one in the speed feedback loop and the other in the current feedback loop.

The outer speed regulator compares the reference speed and the actual rotor speed and processes the speed error to obtain the reference slip speed, which is used to obtain the reference stator active and reactive currents and hence, the reference DC link current. The inner current PI regulator compares the reference and actual DC link currents and adjusts the turn on period of PWM pulses, hence the output voltage of the converter.

\section{Mathematical Modeling}

The modeling of the modified CSI-fed induction motor drive is carried out in synchronously rotating reference frame for the following:

(1) Three-phase PWM rectifier

(2) Three-phase PWM inverter

(3) DC link

(4) Three-phase induction motor with load

(5) Three-phase capacitor bank

\subsection{Three-phase PWM Rectifier}

The PWM rectifier output voltage depends on the number of pulses per cycle and their widths. The converter is modeled for 12 numbers of equal pulses per cycle. It leads to two pulses per $60^{\circ}$ each of $\beta$ width. The average output voltage of the PWM rectifier can be expressed as follows:

$$
V_{r}=\frac{3 \sqrt{2}}{\pi} V_{L L}\left(4 \sin \frac{5 \pi}{12}\right) \sin \frac{\beta}{2}
$$

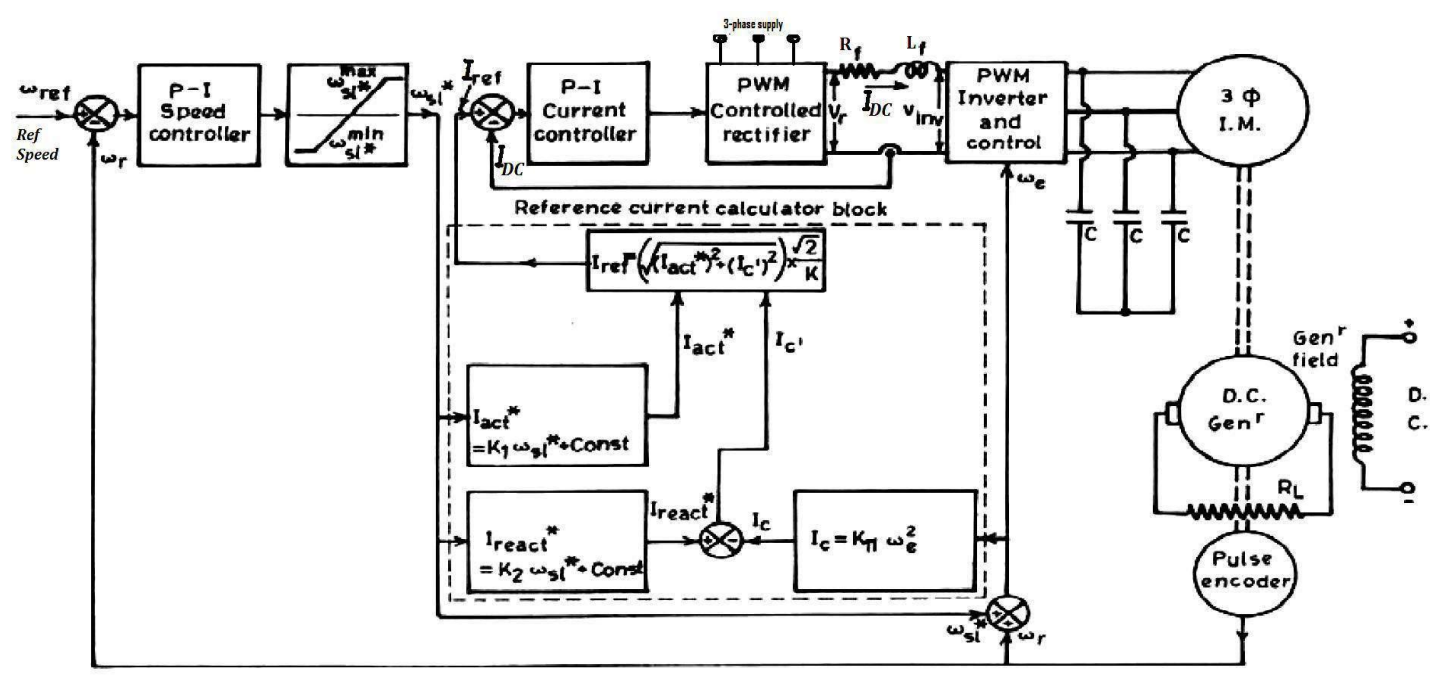

Fig. 1. Variable speed modified current source inverter-fed induction motor drive. 
Since $\beta$ is varied from $10 \%$ to $90 \%$ of $(\pi / 6)$ radians, it can be approximated as follows: $\sin (\beta / 2) \cong(\beta / 2)$

$$
V_{r}=5.218 V_{L L}(\beta / 2)
$$

\subsection{Three-phase PWM Inverter}

The fundamental component of the line currents of the three-phase pulse width modulated inverter $i_{a s}, i_{b s}$, and $i_{c s}$ forms a balanced set of three-phase currents with maximum value as $I_{a s(\max )}$ and can be expressed as follows:

$$
\mathrm{I}_{\mathrm{as}(\max )}=\mathrm{k} \mathrm{I}_{\mathrm{DC}}
$$

Where $k$ is obtained through Fourier analysis of inverter line current waveforms, and this is given by the following:

$$
k=\frac{\text { maximum value of fundamental inverter line current }}{\mathrm{D} C \text { link current }\left(I_{D C}\right)}
$$

The value of $k$ depends on the operating frequency of the inverter and varies from 0.8485 to 0.9970 for variation in operating frequencies from 10 to $50 \mathrm{~Hz}$. Since the inverter output fundamental current peak is taken along the $q^{e}$ axis of the reference frame, the transformed phase current equations in the $q^{e}-d^{e}$ reference frame are as follows:

$$
i_{0 s}{ }^{e}=0 ; i_{q s}{ }^{e}=k I_{D C} \quad ; \quad i_{d s}{ }^{e}=0
$$

Assuming power loss in the inverter to be negligible, i.e., input power = output power, we can derive the following:

$$
V_{i n v} I_{i n v}=v_{a s} i_{a s}+v_{b s} i_{b s}+v_{c s} i_{c s}=\frac{3}{2}\left(v_{q s}{ }^{e} i_{q s}{ }^{e}+v_{d s}{ }^{e} i_{d s}{ }^{e}\right)
$$

Substituting the values of $i_{q s}{ }^{e}, i_{d s}{ }^{e}$, and $I_{i n v}$ in terms of $I_{D C}$, the following equation is obtained:

$$
V_{i n v}=1.5 k v_{q s}^{e}
$$

\subsection{Link}

The rectifier output voltage $V_{r}$ is the sum of the inverter input voltage $V_{i n v}$ and DC link voltage, hence

$$
V_{r}=1.5 k V_{q s}^{e}+\left(R_{f}+p L_{f}\right) I_{D C} .
$$

\subsection{Three-phase Induction Motor}

The induction motor can be modeled in the $q^{e}-d^{e}$ reference frame using the following assumptions:

(1) The three-phase stator windings of the motor are balanced and sinusoidally distributed in space.

(2) The DC link current is ripple free.

(3) The inverter switching transients are ignored.
(4) There is no core loss in the motor.

(5) The motor can be described by fourth-order matrix equation in $q^{e}-d^{e}$ reference frame as follows:

$$
\left[\begin{array}{c}
v_{q s}^{e} \\
v_{d s}^{e} \\
0 \\
0
\end{array}\right]=\left[\begin{array}{cccc}
R_{s}+p L_{s} & \omega_{e} L_{s} & p L_{m} & \omega_{e} L_{m} \\
-\omega_{e} L_{s} & R_{s}+p L_{s} & -\omega_{e} L_{m} & p L_{m} \\
p L_{m} & \omega_{s l} L_{m} & R_{r}+p L_{r} & \omega_{s l} L_{r} \\
-\omega_{s l} L_{m} & p L_{m} & -\omega_{s l} L_{r} & R_{r}+p L_{r}
\end{array}\right]\left[\begin{array}{c}
i_{q s}^{e} \\
i_{d s}^{e} \\
i_{q r}^{e} \\
i_{d r}^{e}
\end{array}\right]
$$

The electromagnetic torque equation of the motor is expressed as follows:

$$
T_{e}=\frac{3}{2} \cdot \frac{P}{2} \cdot L_{m}\left(i_{q s}{ }^{e} i_{d r}{ }^{e}-i_{q r}{ }^{e} i_{d s}{ }^{e}\right)
$$

The equation of motion of the drive is given by the following:

$$
T_{e}=T_{l}+J \frac{d \omega_{r}}{d t}+B \omega_{r}
$$

The load torque equation is expressed as

$$
T_{l}=T_{L} \cdot\left(\omega_{r} / \omega_{\text {base }}\right) .
$$

\subsection{Three-phase Capacitor Bank}

The capacitor current is related to the stator voltage of the induction motor, as shown below:

$$
i_{c}=C \frac{d v_{s}}{d t}
$$

Transforming (12) in the synchronously rotating reference frame $q^{e}-d^{e}$, we have the following:

$$
\left(i_{d c}^{e} \cos \omega_{e} t-i_{q c}^{e} \sin \omega_{e} t\right)=C \frac{d}{d t}\left(v_{d s}^{e} \cos \omega_{e} t-v_{q s}^{e} \sin \omega_{e} t\right)
$$

Differentiating (13) and comparing the terms on both sides, $d$-axis and $q$-axis currents are expressed as follows:

$$
\begin{aligned}
& i_{d c}^{e}=C\left(p v_{d s}^{e}-\omega_{e} v_{q s}^{e}\right) \\
& i_{q c}^{e}=C\left(p v_{q s}^{e}+\omega_{e} v_{d s}^{e}\right)
\end{aligned}
$$

\section{Design of Regulator Parameters}

The transient response of the drive depends on the choice of speed and current regulator parameters, which can be selected on the basis of the stability and response of the drive by applying the D-partition technique [6]. The Dpartition method is used to study the effect of two parameters on the control system on stability and transient performance. With regard to stability analysis, the method 
provides a possibility of defining the relative stability of the control system with the roots of the characteristic equation lying within a specified $p$-plane contour of general shape [9]-[10]. The $p$-plane with two adjustable parameters as coordinate axis is termed as "parametric plane".

For the determination of regulator parameters by the Dpartition technique, the non-linear equations of the system are linearized by the method of small perturbation about the steady-state operating point, and the characteristic equations are developed for both current and speed regulator loops. The D-partition boundaries are plotted in the parametric plane and the probable stable regions are identified in the plane of the proportional and integral gain parameters for both the regulators.

Frequency scanning check is used for further confirmation of the probable stable region obtained from the Dpartition boundaries [6]. To apply this technique, a point from the inside of the probable stable region and a point outside the probable stable region of the D-partition boundary are selected for both current and speed regulators. The real and imaginary parts of the characteristic equation of the current and speed regulators are plotted for the points inside and outside the stable region for varying $\omega$ from $-\infty$ to $+\infty$. If the origin lies inside the hatched curve, the system is stable, whereas if it is outside the hatched region, the system is unstable.

\subsection{Design of Current Regulator}

For the design of current regulator parameters $\left(k_{p_{i}}\right.$ and $k_{i_{i}}$ ), the speed of the motor is assumed to be constant since the mechanical time constant of the motor is much higher than the electrical time constant; hence, $\omega_{s l}^{*}$ and $\omega_{e}$ are also considered as constant for the design of current regulator parameters. With small perturbation in machine-operating variables around steady-state operating points, (rated point) a linear relation in drive variables is obtained. Perturbing the stator voltages, stator currents, rotor currents, rotor voltages, capacitor currents, stator active currents, stator reactive currents, and rotor speed, the final perturbed equations used for the determination of current and speed characteristic equations are as follows:

$$
\begin{gathered}
F_{24}(p) \Delta v_{d s}^{e}-F_{25}(p) \Delta v_{q s}^{e}+k F_{6}(p) \Delta I_{D C}=0 \\
F_{25}(p) \Delta v_{d s}^{e}+F_{24}(p) \Delta v_{q s}^{e}-k F_{5}(p) \Delta I_{D C}=0 \\
\left(k_{p_{i}}+\frac{k_{i_{i}}}{p}+R_{f}+p L_{f}\right) \Delta I_{D C}+\frac{3}{2} k \Delta v_{q s}^{e}=0 \\
F_{18}(p) \Delta v_{d s}^{e}+F_{19}(p) \Delta v_{q s}^{e}+k F_{15}(p) \Delta I_{D C} \\
+\left[-F_{26}(p)\left(k_{p_{s}}+\frac{k_{i_{s}}}{p}\right)-F_{27}(p)\right] \Delta \omega_{r}=0 \\
{\left[F_{24}(p) \Delta v_{d s}^{e}-F_{25}(p) \Delta v_{q s}^{e}\right]=-\left[F_{7}(p) \psi_{d r}^{e}-F_{8}(p) \psi_{q r}^{e}\right.} \\
\left.-F_{22}(p)\right] \Delta \omega_{r}-k F_{6}(p) \Delta I_{D C}+F_{22}(p) \Delta \omega_{s l}
\end{gathered}
$$

$$
\begin{gathered}
{\left[F_{25}(p) \Delta v_{d s}^{e}+F_{24}(p) \Delta v_{q s}^{e}\right]=-\left[F_{8}(p) \psi_{d r}^{e}+\right.} \\
\left.F_{7}(p) \psi_{q r}^{e}-F_{23}(p)\right] \Delta \omega_{r}+F_{23}(p) \Delta \omega_{s l}+k F_{5}(p) \Delta I_{D C} \\
\left(k_{p_{i}}+\frac{k_{i_{i}}}{p}\right)\left[\left\{\left(k_{p_{s}}+\frac{k_{i_{s}}}{p}\right)\left(-A_{1}-A_{2}\right)\right\}+A_{2}\right] \Delta \omega_{r} \\
-\left(k_{p_{i}}+\frac{k_{i_{i}}}{p}+R_{f}+p L_{f}\right) \Delta I_{D C}-\frac{3}{2} k \Delta v_{q s}^{e}=0
\end{gathered}
$$

Expressing (16)-(18) in matrix form, the current regulator matrix equation is given as follows:

$$
\left[\begin{array}{lcc}
0 & 1.5 k & \left(k_{p_{i}}+\frac{k_{i_{i}}}{p}+R_{f}+p L_{f}\right) \\
F_{24}(p) & -F_{25}(p) & k F_{6}(p) \\
F_{25}(p) & F_{24}(p) & -k F_{5}(p)
\end{array}\right]\left[\begin{array}{l}
\Delta v_{d s}^{e} \\
\Delta v_{q s}^{e} \\
\Delta I_{D C}
\end{array}\right]=0
$$

Finally, the characteristic equation of the current regulator matrix is expressed as the below equation:

$$
k_{p_{i}} a_{4}+k_{i_{i}} a_{3}+a_{5}=0
$$

Separating the real and imaginary parts of (24) and solving them, the values for $k_{p_{i}}$ and $k_{i_{i}}$ are given as follows:

$$
\begin{aligned}
& k_{p_{i}}=\frac{\left|\begin{array}{ll}
-a_{5 r} & a_{3 r} \\
-a_{5 i} & a_{3 i}
\end{array}\right|}{\Delta} \\
& k_{i_{i}}=\frac{\left|\begin{array}{cc}
a_{4 r} & -a_{5 r} \\
a_{4 i} & -a_{5 i}
\end{array}\right|}{\Delta}
\end{aligned}
$$

Where $\Delta=a_{4 r} a_{3 i}-a_{4 i} a_{3 r}$

All variables in the characteristic equation are the function of $p$. Substituting $p=(-\sigma+j \omega)$ in (25)-(27) and varying $\omega$ from $-\infty$ to $+\infty$ for $\sigma=0.0$, the Dpartition boundary is plotted in the $\left(k_{p_{i}}, k_{i_{i}}\right)$ plane, as shown in Fig. 2.

The stability of the identified region is confirmed by the frequency scanning technique for the points inside and outside the region. The characteristic vector $D(p)=k_{p_{i}} a_{4}+k_{i_{i}} a_{3}+a_{5}$ is evaluated at a selected point inside this region $\left(\sigma=0.0, k_{p_{i}}=0.9, k_{i_{i}}=278\right)$ and is plotted in real-imaginary plane, as shown in Fig. 3, for varying $\omega$ from $-\infty$ to $+\infty$. The curve of the characteristic vector encloses the origin. Hence, the region is stable and any point in it can be selected.

Another point $\left(\sigma=0.0, k_{p_{i}}=12, k_{i_{i}}=800\right)$ is taken from outside, above the region, and the characteristic vector is plotted as shown in Fig. 4 for varying $\omega$ from $-\infty$ to $+\infty$. The origin is not encircled by the curve and hence, the region outside the curve is unstable. 


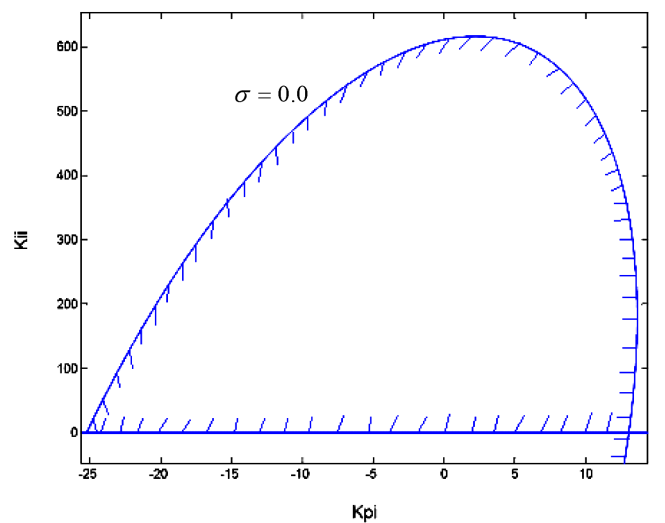

Fig. 2. D-partition boundary of current regulator for $\sigma=0$.

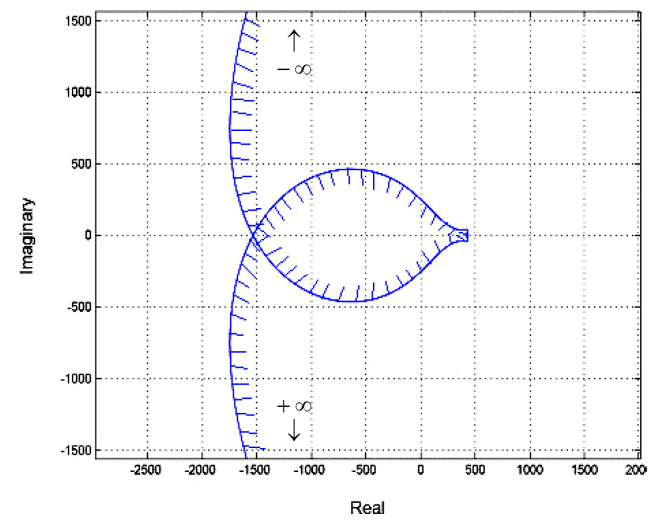

Fig. 3. Stability investigation for the selected point in the region of Fig. 2 using frequency scanning (stable).

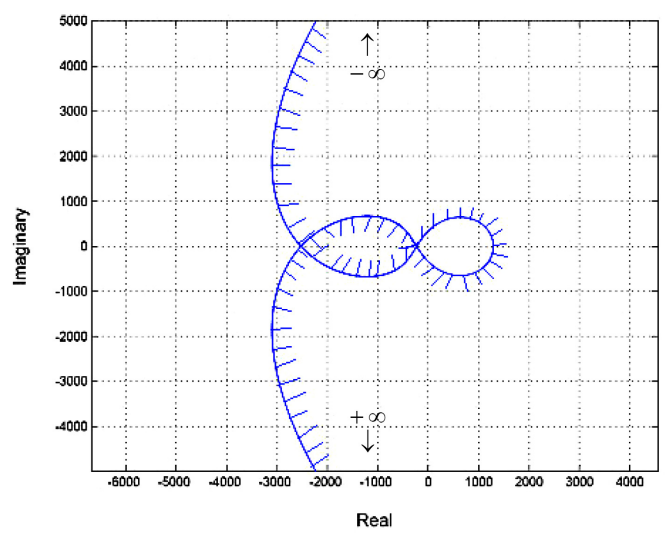

Fig. 4. Stability investigation for the selected point outside the region of Fig. 2 using frequency scanning (unstable).

The $\sigma=0$ gives the probable stable region. As the value of $\sigma$ is continuously increased the probable stable region shrinks, and the most probable stable region is achieved. After a certain value of the $\sigma$, the stable region vanishes. In order to identify the most stable region, the relative Dpartition boundaries are plotted for the different values of $\sigma$ and varying $\omega$ from $-\infty$ to $+\infty$, as shown in Fig. 5. At $\sigma=10$, the most probable stable region is obtained.
The exact decision on current regulator parameters is made by determining the transient response of the current loop for step variation in reference current from 1.0 to 1.05 of the rated current. The transient response curves for the current loop are plotted for different sets of $k_{p_{i}}$ and $k_{i_{i}}$ values, which were chosen from the most probable stable region of Fig. 5. The parameters, for which the settling time and percentage peak overshoot are moderate, are finally selected as regulator parameters.

The transient response curves are shown in Fig. 6, which correspond to the different sets of $k_{p_{i}}$ and $k_{i_{i}}$ values chosen from the most probable stable region of Fig. 5. The magnified curves are shown in Fig. 7. The settling time and percentage overshoot corresponding to these chosen values of $k_{p_{i}}$ and $k_{i_{i}}$ are shown in Table 1.

The comparison of various transient response curves shows that for $\left(k_{p_{i}}=0.9\right.$ and $\left.k_{i_{i}}=278.0\right)$, the response is fastest and the percentage peak overshoot is the minimum. Hence, the selected transfer function of current regulator is given by $\left(0.9+\frac{278}{p}\right)$.

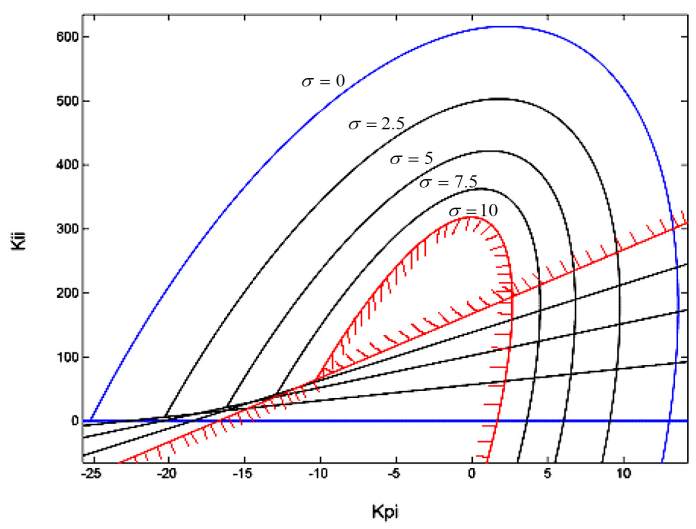

Fig. 5. D-partition boundary of current regulator for different values of $\sigma$.

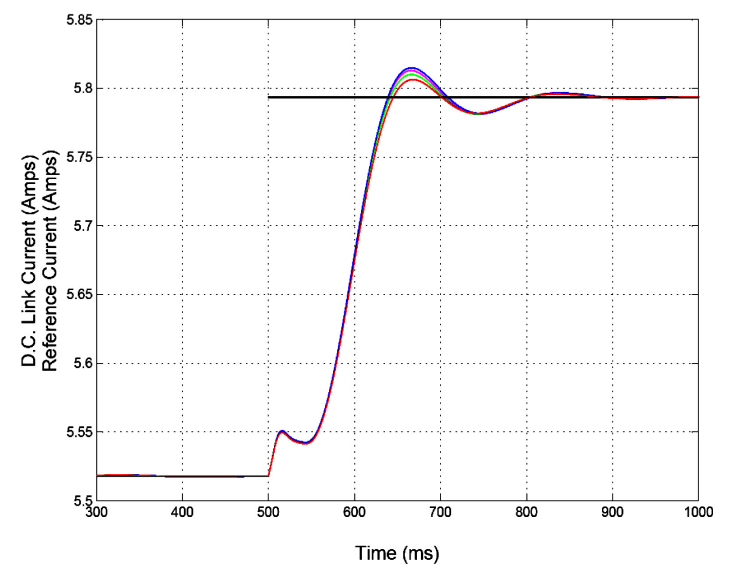

Fig. 6. Transient response of the current loop for different sets of $k_{p_{i}}$ and $k_{i_{i}}$. 


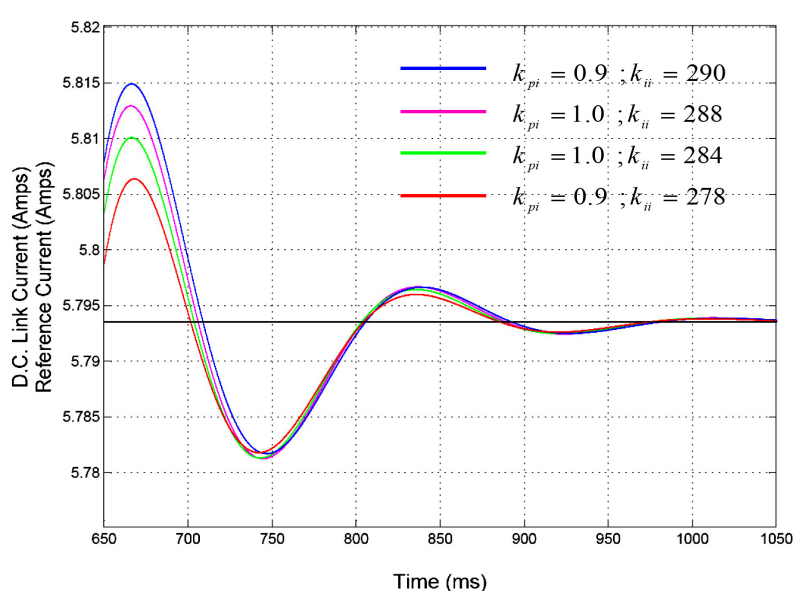

Fig. 7. Magnified view of the transient response of the current loop.

Table 1. Settling time and percentage overshoot corresponding to different sets of $k_{p_{i}}$ and $k_{i_{i}}$ values

\begin{tabular}{c|c|c|c|c}
\hline Sr. & $k_{p_{i}}$ & $k_{i_{i}}$ & $\begin{array}{c}\text { Settling time } \\
(\mathrm{ms})\end{array}$ & Peak overshoot \\
\hline 1 & 0.9 & 290 & 417 & $0.37 \%$ \\
\hline 2 & 1.0 & 288 & 418 & $0.34 \%$ \\
\hline 3 & 1.0 & 284 & 416 & $0.28 \%$ \\
\hline 4 & 0.9 & 278 & 415 & $0.22 \%$ \\
\hline
\end{tabular}

\subsection{Design of Speed Regulator}

Expressing (19)-(22) in matrix form, the speed regulator matrix equation is given as follows:

$$
\begin{aligned}
& {\left[\begin{array}{ccc}
F_{18}(p) & F_{19}(p) & -F_{26}(p)\left(k_{p_{s}}+\frac{k_{i_{s}}}{p}\right)-F_{27}(p) \\
F_{24}(p) & -F_{25}(p) & F_{7}(p) \psi_{d r}^{e}-F_{8}(p) \psi_{q r}^{e}+\left(k_{p_{s}}+\frac{k_{i_{s}}}{p}-1\right) F_{22}(p) \\
F_{25}(p) & F_{24}(p) & F_{8}(p) \psi_{d r}^{e}+F_{7}(p) \psi_{q r}^{e}+\left(k_{p s}+\frac{k_{i_{s}}}{p}-1\right) F_{23}(p) \\
0 & -1.5 k & \left(k_{p_{i}}+\frac{k_{i i}}{p}\right)\left[\left\{\left(k_{p_{s}}+\frac{k_{i_{s}}}{p}\right)\left(-A_{1}-A_{2}\right)\right\}+A_{2}\right]
\end{array}\right.} \\
& \left.\begin{array}{c}
k F_{15}(p) \\
k F_{6}(p) \\
-k F_{5}(p) \\
-\left(k_{p_{i}}+\frac{k_{i i}}{p}+R_{f}+p L_{f}\right)
\end{array}\right]\left[\begin{array}{c}
\Delta v_{d s}^{e} \\
\Delta v_{q s}^{e} \\
\Delta \omega_{r} \\
\Delta I_{D c}
\end{array}\right]=0
\end{aligned}
$$

The characteristic equation of the current regulator matrix is expressed as follows:

$$
k_{p_{s}} c_{33}+k_{i_{s}} c_{31}+c_{34}=0
$$

Separating the real and imaginary parts of (29) and solving them, the values for $k_{p_{s}}$ and $k_{i_{s}}$ are given as the following:

$$
\begin{aligned}
k_{p_{s}} & =\frac{\left|\begin{array}{ll}
-c_{34 r} & c_{31 r} \\
-c_{34 i} & c_{31 i}
\end{array}\right|}{\Delta} \\
k_{i_{s}} & =\frac{\left|\begin{array}{ll}
c_{33 r} & -c_{34 r} \\
c_{33 i} & -c_{34 i}
\end{array}\right|}{\Delta}
\end{aligned}
$$

Where $\Delta=c_{33 r} c_{31 i}-c_{31 r} c_{33 i}$.

Using (30)-(32) and varying $\omega$ from $-\infty$ to $+\infty$, for $\sigma=0.0$, the D-partition boundary is plotted in the $\left(k_{p_{s}}, k_{i_{s}}\right)$ plane, as shown in Fig. 8. Any point lying within the shaded region may be considered as a stable point. The stability of the identified region is confirmed by the frequency scanning technique for points inside and outside this region. The characteristic vector $D(p)=k_{p_{s}} c_{33}+k_{i_{s}} c_{31}+c_{34}$ is evaluated at a selected point inside the region $\left(\sigma=0.0, k_{p_{s}}=0.23, k_{i_{s}}=0.32\right)$ and is plotted in realimaginary plane by varying $\omega$ from $-\infty$ to $+\infty$, as shown in Fig. 9. The curve of the characteristic vector encloses the origin. Hence, the region is stable and any point in it can be selected.

Another point $\left(\sigma=0.0, k_{p_{s}}=2, k_{i_{s}}=5\right)$ is taken from outside, above the region, and the characteristic vector is plotted, as shown in Fig. 10 for varying $\omega$ from $-\infty$ to $+\infty$. The origin is not encircled by the curve and hence, the region outside the curve is unstable. In order to get most stable region, the relative D-partition boundaries are plotted for the different values of $\sigma$ and varying $\omega$ from $-\infty$ to $+\infty$, as shown in Fig. 11. At $\sigma=2.76$, the most probable stable region is obtained.

The exact decision on speed regulator parameters can be made by determining the transient response of the speed loop for the step variation in the reference speed from 1.0 to 1.05 of the rated speed. The transient response curves for

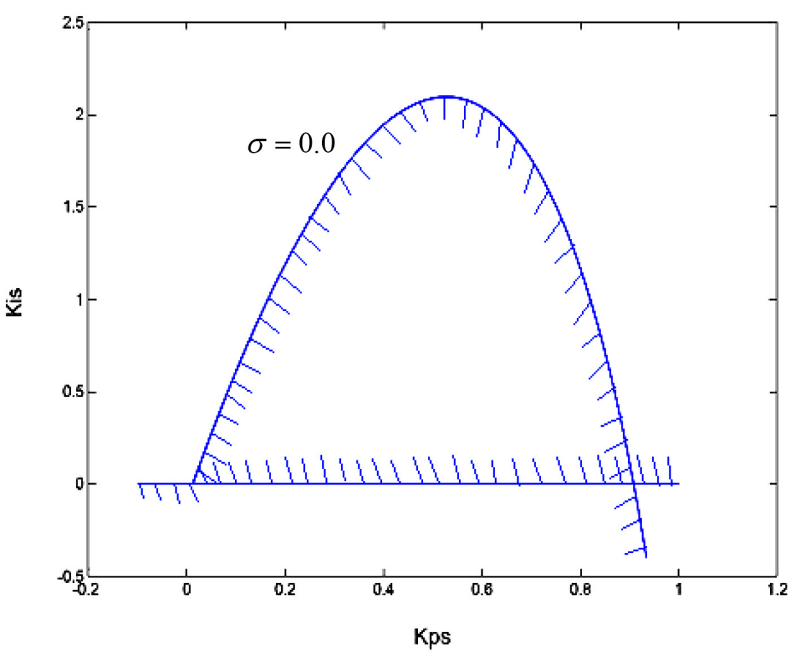

Fig. 8. D-partition boundary of speed regulator for $\sigma=0$. 


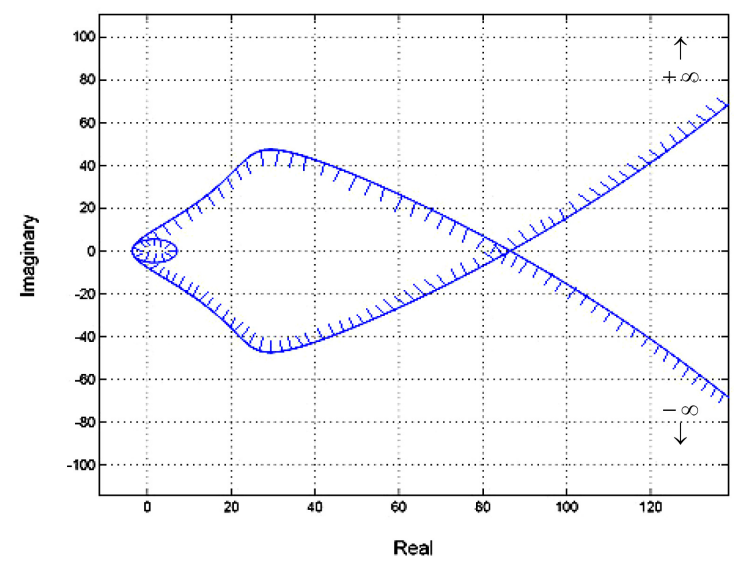

Fig. 9. Stability investigation for the selected point in the region of Fig. 8 using frequency scanning (stable).

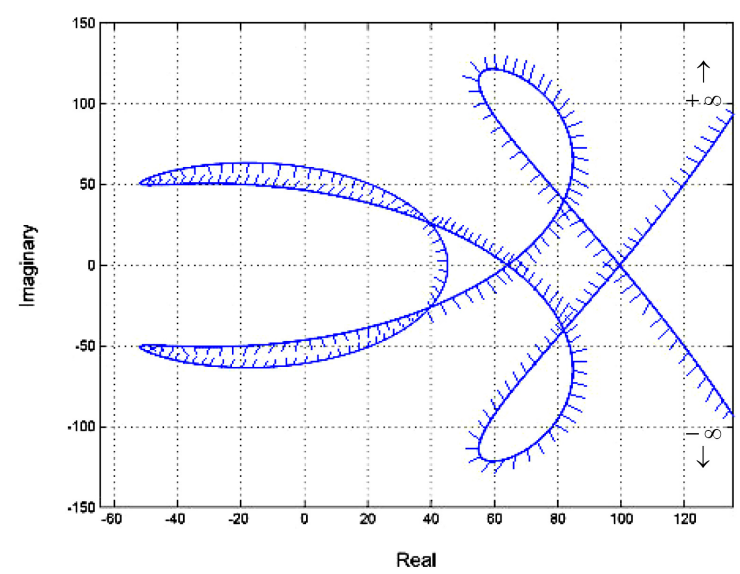

Fig. 10. Stability investigation for the selected point outside the region of Fig. 8 using frequency scanning (unstable).

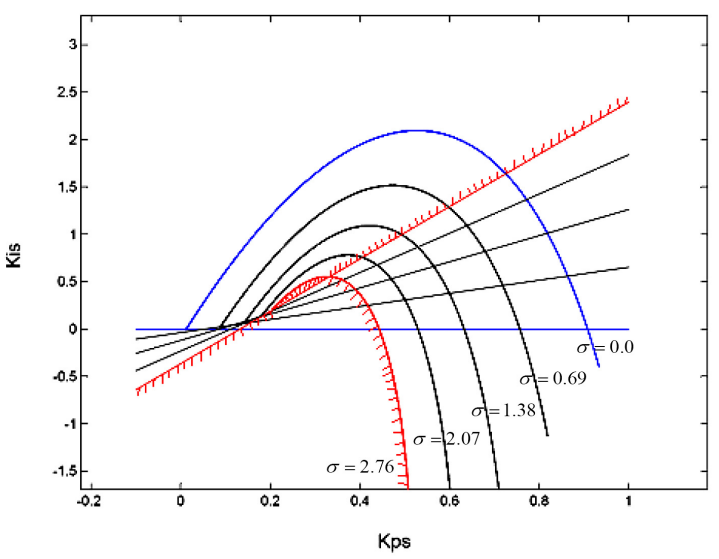

Fig. 11. D-partition boundary of speed regulator for different values of $\sigma$.

the speed loop are plotted for the different sets of $k_{p_{s}}$ and $k_{i_{s}}$ values chosen from the most probable stable region of Fig. 11. The parameters for which the settling time and percentage peak overshoot are moderate are finally selected as regulator parameters.
The transient response curves are shown in Fig. 12, which corresponds to different sets of $k_{p_{s}}$ and $k_{i_{s}}$ values chosen from the most probable stable region of Fig. 11. The magnified curves are shown in Fig. 13. The settling time and percentage overshoot corresponding to these chosen values of $k_{p_{s}}$ and $k_{i_{s}}$ are shown in Table 2.

The transient response curves show that for $\left(k_{p_{s}}=0.23\right.$ and $\left.k_{i_{s}}=0.32\right)$, the percentage peak overshoot is within the permissible tolerance limit and the settling time is near the fastest. Hence, the transfer function of the speed regulator is given by $\left(0.23+\frac{0.32}{p}\right)$.

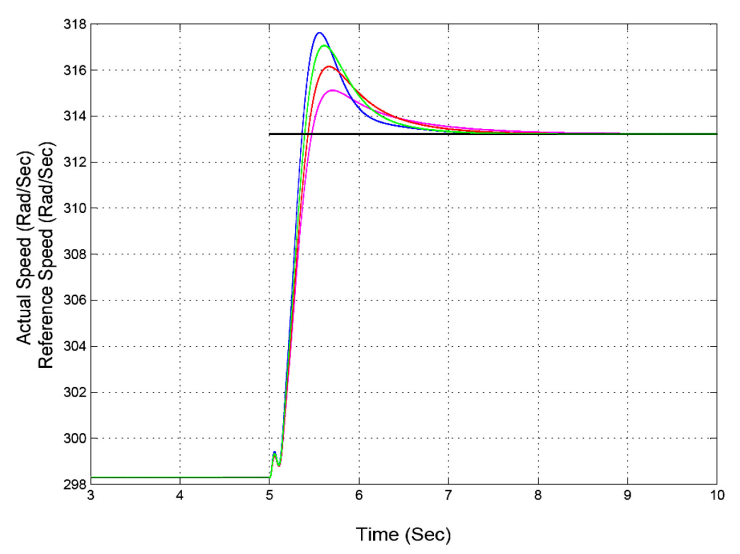

Fig. 12. Transient response of the speed loop for different sets of $k_{p_{s}}$ and $k_{i_{s}}$.

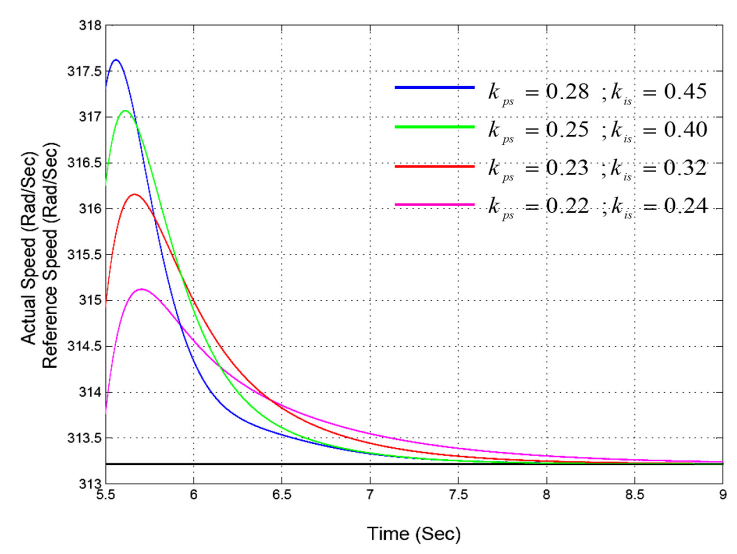

Fig. 13. Magnified view of the transient response of the speed loop.

Table 2. Settling time and percentage overshoot corresponding to various values of $k_{p_{s}}$ and $k_{i_{s}}$

\begin{tabular}{c|c|c|c|c}
\hline Sr. & $k_{p_{s}}$ & $k_{i s}$ & Settling time (s) & Peak overshoot \\
\hline 1 & 0.28 & 0.45 & 2.2 & $1.41 \%$ \\
\hline 2 & 0.25 & 0.40 & 2.2 & $1.23 \%$ \\
\hline 3 & 0.23 & 0.32 & 2.4 & $0.94 \%$ \\
\hline 4 & 0.22 & 0.24 & 2.7 & $0.62 \%$ \\
\hline
\end{tabular}




\section{Performance Investigation of the Drive}

Having designed the parameters of both current and speed regulators, the performance of the drive is investigated through MATLAB simulation by implementing the designed values of regulator parameters and analyzing the current and speed transient responses of the drive for different step variations in reference speed. The current and speed transient responses of the drive for step changes in reference speed each after an interval of 10 seconds are shown in Figs. 14-15.

The effectiveness of both regulators can be demonstrated by considering the current and speed transient responses of the drive separately for each alteration in reference speed. Figs. (16)-(19) show the current transient responses of the drive separately for step changes in reference speed from $200 \mathrm{rad} / \mathrm{s}$ to $250 \mathrm{rad} / \mathrm{s}, 250 \mathrm{rad} / \mathrm{s}$ to $298.2999 \mathrm{rad} / \mathrm{s}$, $298.2999 \mathrm{rad} / \mathrm{s}$ to $250 \mathrm{rad} / \mathrm{s}$, and $250 \mathrm{rad} / \mathrm{s}$ to $200 \mathrm{rad} / \mathrm{s}$, respectively. Figs. (20)-(23) show the speed transient responses of the drive separately for step changes in reference speed from $200 \mathrm{rad} / \mathrm{s}$ to $250 \mathrm{rad} / \mathrm{s}, 250 \mathrm{rad} / \mathrm{s}$ to $298.2999 \mathrm{rad} / \mathrm{s}, 298.2999 \mathrm{rad} / \mathrm{s}$ to $250 \mathrm{rad} / \mathrm{s}$, and $250 \mathrm{rad} / \mathrm{s}$ to $200 \mathrm{rad} / \mathrm{s}$, respectively.

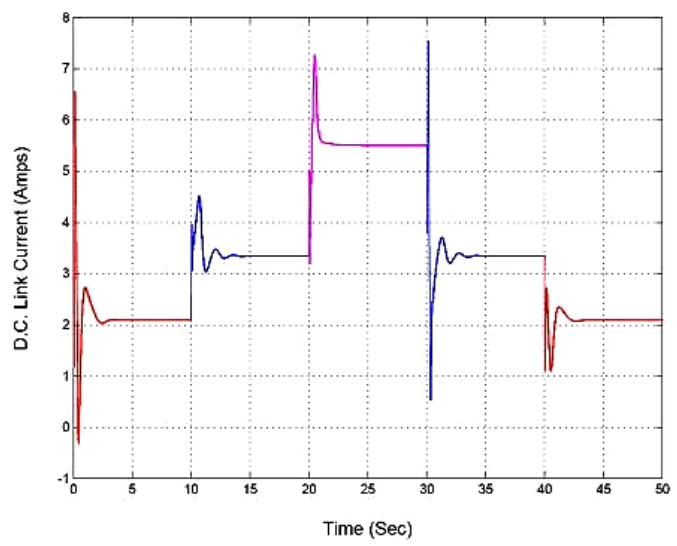

Fig. 14. Current transient response of the drive for step changes in reference speed each after an interval of 10 seconds.

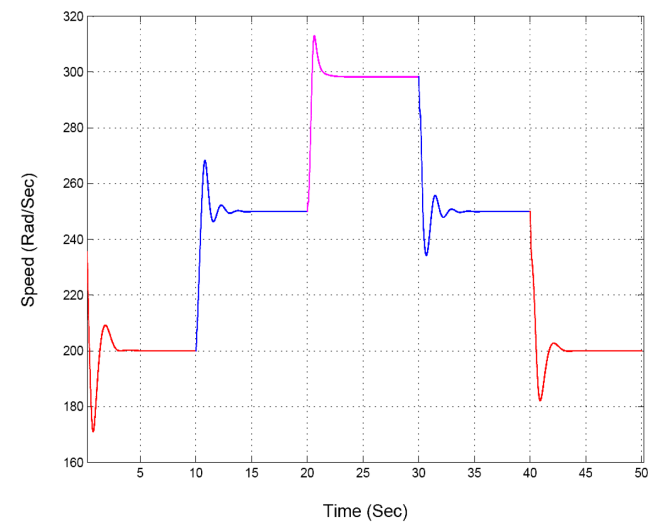

Fig. 15. Speed transient response of the drive for step changes in reference speed each after an interval of 10 seconds.
These response curves show that the settling time of the drive for the designed values of regulator parameters and for the different step variations in reference speed are 3.7, $2.8,3.6$, and 3.1 seconds, respectively. This shows the effectiveness of the closed loop operation of the drive at the designed speed and current regulator parameters.

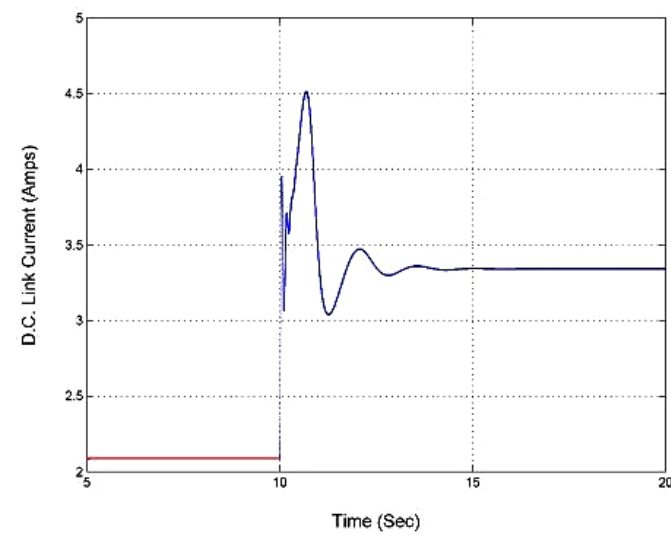

Fig. 16. Current transient response of the drive for step changes in reference speed from $200 \mathrm{rad} / \mathrm{s}$ to $250 \mathrm{rad} / \mathrm{s}$.

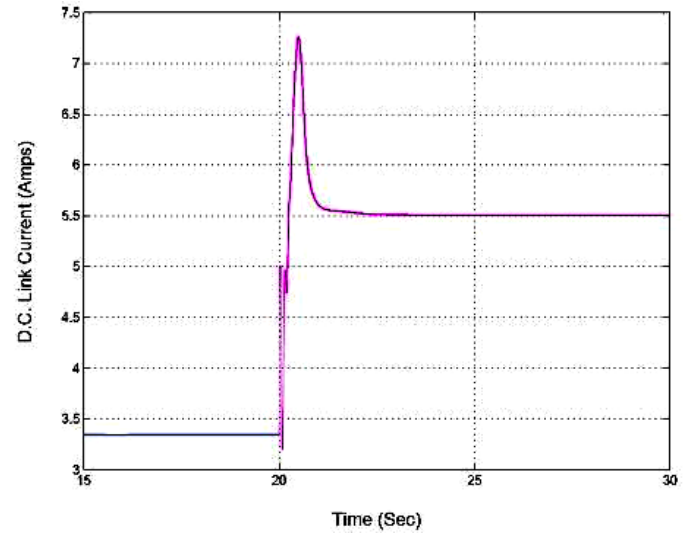

Fig. 17. Current transient response of the drive for step changes in reference speed from $250 \mathrm{rad} / \mathrm{s}$ to $298.2999 \mathrm{rad} / \mathrm{s}$

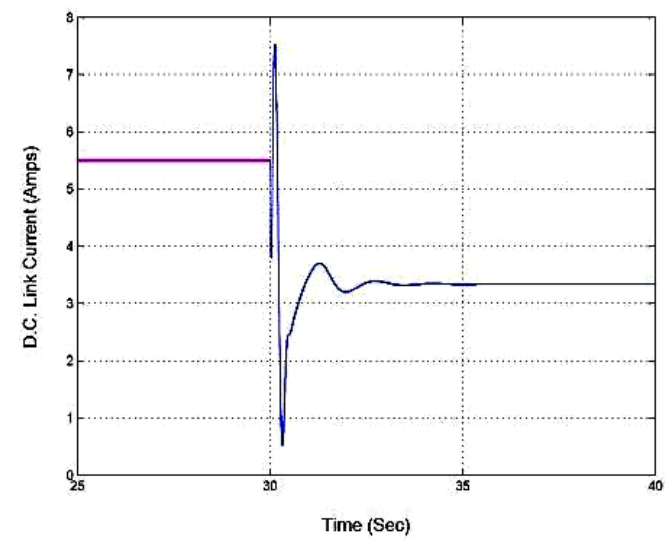

Fig. 18. Current transient response of the drive for step changes in reference speed from $298.2999 \mathrm{rad} / \mathrm{s}$ to $250 \mathrm{rad} / \mathrm{s}$. 


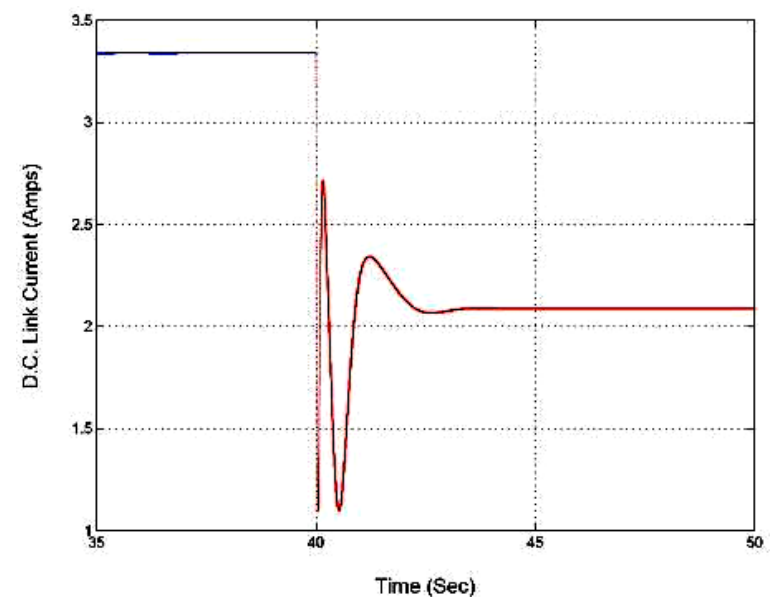

Fig. 19. Current transient response of the drive for step changes in reference speed from $250 \mathrm{rad} / \mathrm{s}$ to $200 \mathrm{rad} / \mathrm{s}$.

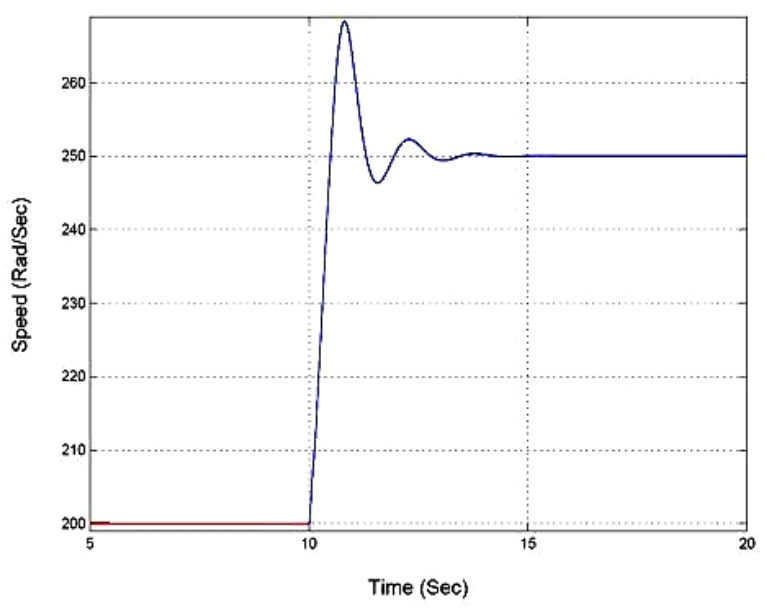

Fig. 20. Speed transient response of the drive for step changes in reference speed from $200 \mathrm{rad} / \mathrm{s}$ to $250 \mathrm{rad} / \mathrm{s}$.

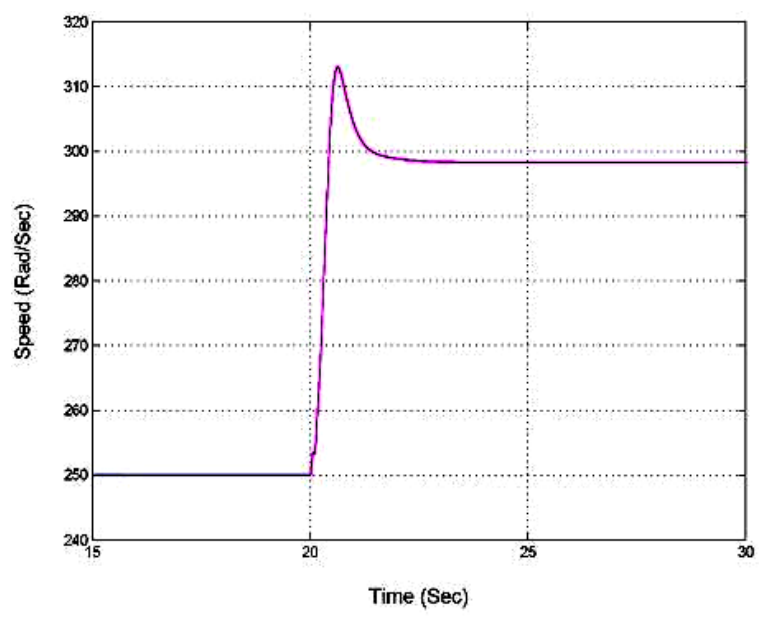

Fig. 21. Speed transient response of the drive for step changes in reference speed from $250 \mathrm{rad} / \mathrm{s}$ to $298.2999 \mathrm{rad} / \mathrm{s}$.

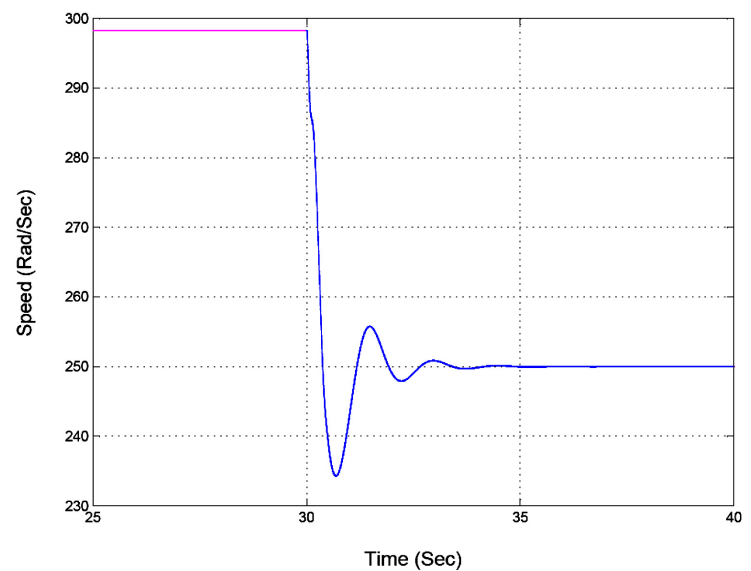

Fig. 22. Speed transient response of the drive for step changes in reference speed $298.2999 \mathrm{rad} / \mathrm{s}$ to $250 \mathrm{rad} / \mathrm{s}$.

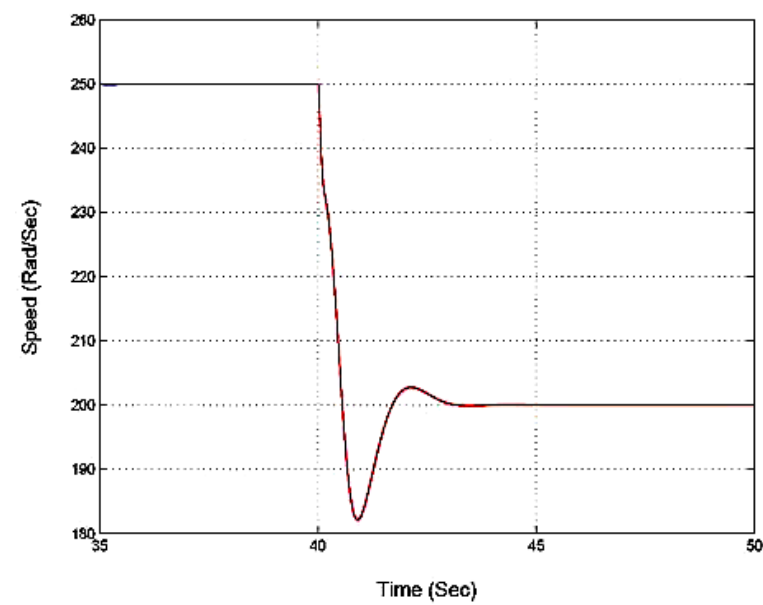

Fig. 23. Speed transient response of the drive for step changes in reference speed from $250 \mathrm{rad} / \mathrm{s}$ to $200 \mathrm{rad} / \mathrm{s}$.

\section{Conclusions}

The D-partitioning technique was applied to determine the current and speed regulator parameters. The characteristic equations needed for the determination of the parameters was obtained by perturbing the machine variables around the rated conditions. The most probable region was obtained by plotting the parametric plane for the different values of $\sigma$. The frequency scanning check was applied to further confirm the stable region. The final selection of regulator parameters was carried out by determining the transient response of the current and speed loops of the drive. With the regulator parameters obtained by the Dpartitioning technique, the effectiveness of the closed loop operation of the drive at designed speed and current regulator parameters was analyzed for different step variations in the reference speed. 


\section{Appendix}

\section{Name plate ratings of induction motor}

$1 \mathrm{HP}$, three-phase, $400 \mathrm{~V}, 50 \mathrm{~Hz}$, four-pole, 1425 r.p.m., star connected

\section{Induction motor parameters}

$R_{s}=3.520 \Omega \quad R_{r}=2.780 \Omega \quad L_{s}=0.165 \mathrm{H}$

$L_{r}=0.165 \mathrm{H} \quad L_{m}=0.150 \mathrm{H} \quad J=0.01289 \mathrm{~kg}-\mathrm{m}^{2}$

\section{DC link parameters}

$R_{f}=0.250 \Omega, \quad L_{f}=0.040 \mathrm{H}$

\section{Functional values and constants}

$$
\begin{aligned}
& F_{1}(p)=\frac{Z_{r}(p)}{\left[\left(Z_{r}(p)\right)^{2}+\omega_{s l}^{2} L_{r}^{2}\right]} \\
& F_{2}(p)=\frac{-\omega_{s l} L_{r}}{\left[\left(Z_{r}(p)\right)^{2}+\omega_{s l}^{2} L_{r}^{2}\right]} \\
& F_{3}(p)=p F_{1}(p)-\omega_{s l} F_{2}(p) \\
& F_{4}(p)=\omega_{s l} F_{1}(p)+p F_{2}(p) \\
& F_{5}(p)=Z_{s}(p)-p L_{m}^{2} F_{3}(p)+L_{m}^{2} F_{4}(p) \omega_{c} \\
& F_{6}(p)=\omega_{e} L_{s}-\omega_{e} L_{m}^{2} F_{3}(p)-p L_{m}^{2} F_{4}(p) \\
& F_{7}(p)=L_{m}\left[p F_{2}(p)+\omega_{e} F_{1}(p)\right] \\
& F_{8}(p)=L_{m}\left[-p F_{1}(p)+\omega_{e} F_{2}(p)\right] \\
& F_{9}(p)=-L_{m} F_{3}(p) \\
& F_{10}(p)=-L_{m} F_{4}(p) \\
& F_{11}(p)=L_{m} F_{4}(p) \\
& F_{12}(p)=-L_{m} F_{3}(p) \\
& F_{13}(p)=\left[F_{2}(p) \psi_{d r}^{e}+F_{1}(p) \psi_{q r}^{e}\right] \\
& F_{14}(p)=\left[-F_{1}(p) \psi_{d r}^{e}+F_{2}(p) \psi_{q r}^{e}\right] \\
& F_{15}(p)=\frac{3}{2} \cdot \frac{P}{2} \cdot L_{m}\left[i_{d r}^{e}+F_{11}(p) i_{q s}^{e}-F_{12}(p) i_{d s}^{e}\right] \\
& F_{16}(p)=\frac{3}{2} \cdot \frac{P}{2} \cdot L_{m}\left[-i_{q r}^{e}+F_{9}(p) i_{q s}^{e}-F_{10}(p) i_{d s}^{e}\right] \\
& F_{17}(p)=\frac{3}{2} \cdot \frac{P}{2} \cdot L_{m}\left[F_{13}(p) i_{q s}^{e}-F_{14}(p) i_{d s}^{e}\right] \\
& F_{18}(p)=-C\left[F_{15}(p) \omega_{e}+p F_{16}(p)\right] \\
& F_{19}(p)=-C\left[p F_{15}(p)-\omega_{e} F_{16}(p)\right] \\
& F_{20}(p)=-C\left[F_{15}(p) v_{d s}^{e}-F_{16}(p) v_{q s}^{e}\right] \\
& F_{21}(p)=F_{17}(p)+J \frac{2}{P} \cdot p \\
& F_{22}(p)=\left[-\psi_{q s}^{e}+C F_{5}(p) v_{q s}^{e}+C F_{6}(p) v_{d s}^{e}+F_{7}(p) \psi_{d r}^{e}-F_{8}(p) \psi_{q r}^{e}\right] \\
& F_{23}(p)=\left[\psi_{d s}^{e}-C F_{5}(p) v_{d s}^{e}+C F_{6}(p) v_{q s}^{e}+F_{8}(p) \psi_{d r}^{e}+F_{7}(p) \psi_{q r}^{e}\right] \\
& F_{24}(p)=1+C\left[p F_{5}(p)-\omega_{e} F_{6}(p)\right] \\
& F_{25}(p)=C\left[\omega_{e} F_{5}(p)+p F_{6}(p)\right] \\
& A_{1}=\frac{I_{a c t}^{*} \times k_{1} \times 2}{k^{2} I_{r e f}} \\
& A_{2}=\frac{-\left(I_{\text {react }}^{*}-I_{c}\right) \times k_{12} \times 2}{k^{2} I_{\text {ref }}} \\
& a_{1}=\left[F_{24}(p) F_{5}(p)+F_{6}(p) F_{25}(p)\right] \\
& a_{2}=R_{f}+p L_{f}
\end{aligned}
$$

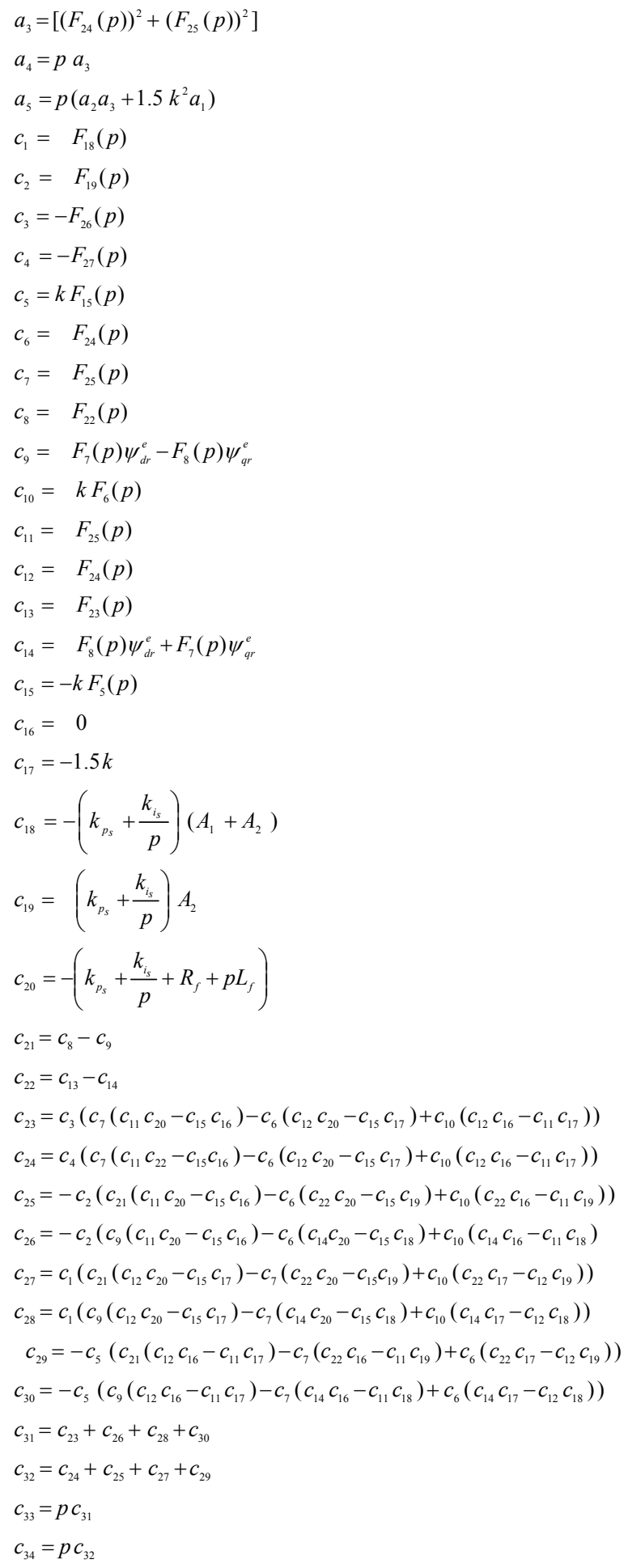

\section{References}

[1] P. Agarwal and V. K. Verma, "Performance Evaluation of Current Source Inverter- Fed Induction Motor Drive", Journals of Institution of Engineers, Vol.72, pp.209-217, February 1992.

[2] P. N. Enjeti, P. D. Ziogas and J. F. Lindsay, "Pro- 
grammed PWM technique to eliminate harmonics: A critical evaluation", IEEE Transactions on Industry Applications, Vol. 26, No. 2, pp. 302-315, March/ April 1990.

[3] S. R. Bowes and R. I. Bullough, "Optimal PWM Microprocessor Controlled Current-Source Inverter Drives", IEEE proceedings, Vol. 135, Pt. B, No. 2, pp. 59-75, March 1988.

[4] Y. Xiao, B. Wu, S. Rizzo and R. Sotuden, "A Novel Power Factor Control Scheme for High Power GTO Current Source Converter", Conference Record IEEE-IAS, pp.865-869, 1996.

[5] Pramod Agarwal, V. K. Verma and A. K. Pandey, "Performance Evaluation of a Self-Commutating CSI-Fed Induction Motor Drive for Different Operating Conditions, IETE Journal of Research, Vol. 54, Issue 4, July/Aug. 2008.

[6] P. Agarwal and V. K. Verma, "Parameter Coordination of Microcomputer Controlled CSI Fed Induction Motor Drive", IE (I) Journal - EL, Vol. 88, December 2007.

[7] A. K. Pandey, Pramod Agarwal and V. K. Verma, "Optimal Capacitor Selection for Modified Self Commutated CSI-fed Induction Motor Drive", IEEE ISIE 2006, Montreal, Quebec, Canada, pp. 1166-1171, July 9-12, 2006.

[8] Pramod Agarwal, A. K. Pandey and V. K. Verma, "Performance Investigation of Modified SelfCommutated CSI-fed Induction Motor Drive, Asian Power Electronics Journal, Vol. 3, No. 1, pp. 21-29, Sept 2009.

[9] J. Nanda, "Analysis of Steady State Stability of a Two Machine System by the D-Composition Technique", IEEE Transactions of Power Apparatus and Systems, Vol. 90, pp. 1848-1855, July / Aug. 1971.
[10] M. A. Aizerman, "Theory of Automatic Control", Chapter -3, Pergamon Press, New York, 1963.

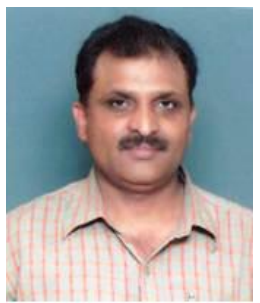

Ashok Kumar Pandey received his Ph.D. degree in Electrical Engineering from Indian Institute of Technology, Roorkee in 2003. He did his M. Tech. in Power Electronics, Electrical Machines and Drives from Indian Institute of Technology, Delhi in 1995. Currently, he is working as an Associate Professor with the Department of Electrical Engineering at Madan Mohan Malaviya Engineering College, Gorakhpur, (U.P.), India. His areas of interest include power electronics, electrical machines, and drives. He is a fellow of Institution of Engineers, India (IE) and Institution of Electronics and Telecommunication Engineers, India (IETE).

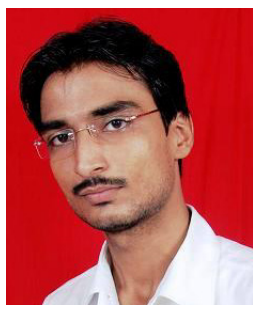

Saurabh Mani Tripathi is presently working as Assistant Professor of Electrical Engineering at Kamla Nehru Institute of Technology, Sultanpur, (U.P.), India. He obtained his B. Tech. degree in Electrical and Electronics Engineering in 2006 and did his M. Tech. in Power Electronics and Drives in 2009 from U.P. Technical University, Lucknow. He has authored several books on modern control system and basic system analysis. His areas of interest include electrical machines, control systems, power electronics, and electric drives. 